\title{
VALIDATION OF AN ANALYTICAL DISPLACEMENT-BASED PUSHOVER FOR MULTI-SPAN CONTINUOUS DECK BRIDGES
}

\author{
Andrea Nettis ${ }^{1}$, Roberto Gentile ${ }^{2}$, Giuseppina Uva ${ }^{1}$ and Domenico Raffaele ${ }^{1}$ \\ ${ }^{1}$ Department of Civil, Environmental, Territorial, Building Engineering and Chemistry \\ Polytechnic University of Bari, Bari, Italy \\ e-mail: \{a.nettis, d.raffaele, g.uva\} @ poliba.it \\ ${ }^{2}$ Institute for Risk and Disaster Reduction \\ University College London, London, UK \\ r.gentile@ucl.ac.uk
}

\begin{abstract}
In the framework of seismic vulnerability assessment, the displacement-based analytical approaches allow the investigation of the non-linear response of structures with accuracy and low computational effort. This paper deals with a recently-proposed displacement-based analytical pushover addressed to the seismic performance assessment of multi-span continuousdeck straight bridges. The method consists in the static analysis of a simplified mechanical model for increased displacements (pseudo pushover) and allows to obtain an "adaptive" force-displacement curve. This procedure is applied to a set of 36 short bridge configurations representing typical Italian typologies (2 to 6 bays, with two deck configurations and different height of the piers). This work aims to test the method for different hazard intensities, also discussing the influence of bridge regularity in the predicted seismic performance. The accuracy of the DBA procedure is evaluated comparing it with more refined pushover and nonlinear time history analyses. Three different suites of 10 natural ground motions, scaled to different intensity levels, are adopted. The results are discussed in terms of capacity/demand checks and predicted deformed shape, proving that the DB pseudo pushover provides approximately the same level of accuracy expected for standard non-linear static analyses.
\end{abstract}

Keywords: Seismic Assessment, Displacement-based Assessment, Pushover analysis, Timehistory analysis, Simplified Mechanical Model, RC continuous-deck bridges. 


\section{INTRODUCTION}

In seismic-prone countries, the performance of bridges and viaducts under earthquake condition assumes a key role for the robustness of the transportation network, and it influences the resilience of entire populated areas. Since most of these structures were built without effective seismic criteria, their seismic performance assessment is essential. For this goal, non-linear time history analysis or non-linear static analysis methods can be effectively adopted. These are considered reliable to investigate the performance of bridges subjected to ground motions, although they require a considerable computational effort, a skill-demanding modelling phase and effort in interpreting the results.

In the last two decades, Displacement-Based Assessment (DBA) procedures were proposed as an innovative assessment method, joining simplicity and reliability. Firstly, Priestley proposed DBA procedures [1] focusing on SDoF systems and multi-storey buildings. Recently, Şadan developed a DBA strategy for the transverse response of bridges [2] based on the effective modal analysis (EMS) previously proposed by Kowalsky for the direct displacement-based design of bridges [3]. This approach is addressed only to single-column bridge with pinned deck-abutment connections and proves a satisfactory accuracy compared to classical forcebased assessment approaches. Moreover, Cardone [4] provided performance displacement profiles corresponding to the Ultimate Limit State (ULS) of different bridge components, comprising abutments, bearings and shear keys. Advances in the issue have been also proposed accounting for soil-structure interaction [5].

In this paper, a DB pseudo-pushover procedure recently-proposed by Gentile et al. [6] is discussed, which allows obtaining the full force-displacement capacity curve of continuous deck straight bridges in a displacement-based fashion, with low computational effort. A static and a modal analysis-based versions of this DB pseudo-pushover were proposed and tested on a set of short RC bridges, and successfully compared to numerical pushover and time-history analyses. The authors proved the accuracy of these approaches considering severe hazard conditions, providing similar results in terms of predicted performance, if compared to a standard (first mode loading) pushover analysis.

In this paper, the static analysis based-DB approach is firstly described and then applied on a dataset of 36 typical Italian bridges configurations having different deck typology, height of the (mono)piers and number of spans. The applicability of the analytical DB pseudo pushover is investigated for three different ground motion intensity levels, considering three different suites of 10 natural scaled ground motions. To this aim, the procedure is compared to more refined numerical pushover and time history analyses. A relatively-simple analytical model is needed, and therefore the procedure can be implemented in a spreadsheet. However, for this work the procedure is implemented in a simple MATLAB [7] function, proving the low computational effort required.

\section{DESCRIPTION OF THE PROPOSED DISPLACEMENT-BASED PROCEDURE}

In this section, the Displacement-Based Pseudo-Pushover procedure (DBPP) is described. The procedure is developed for analysing the transverse seismic response of RC multi-span continuous deck bridges, which are one of the most widespread bridge typologies in the Italian context, together with RC multi-span simply supported bridges. This latter less-complex typology is not considered in this work, although more research effort is needed to validate the DBPP in this context. In fact, the seismic response of such typology can be analysed with one or more SDoF systems related to each pier [8], [9]. The DBPP, described in Fig.1, is able to provide a 


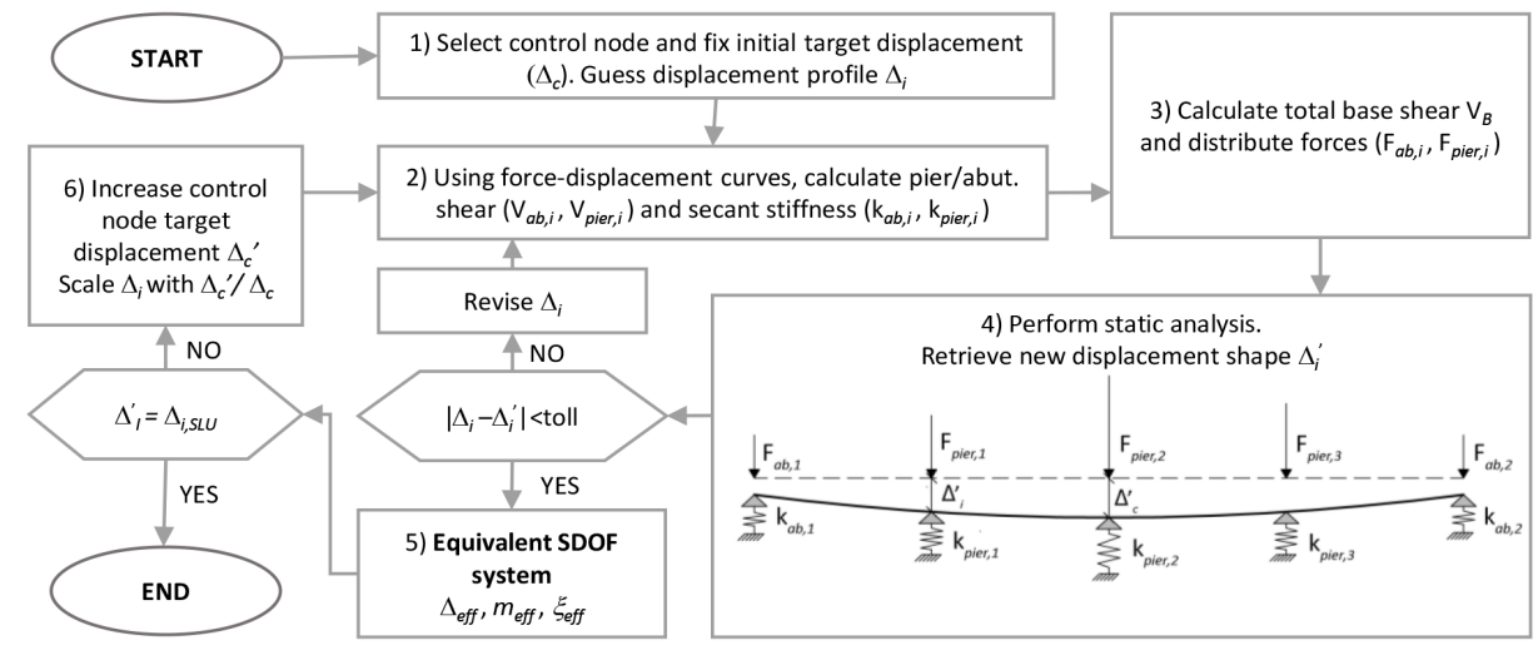

Figure 1 : Flowchart of the static analysis-based DB pseudo-pushover

full force-displacement curve of the investigated bridge. The basic concept can be referred to the pseudo-pushover technique, reported in international guidelines [10], that comprises many linear static analysis, performed increasing the magnitude of the acting inertia force profile and updating the secant stiffness of the members according to their ductility demand.

The DBPP is performed through repeated static analyses of a simplified bridge model to derive the deck displacement profile associated to the (increasing) target displacement of a predetermined control node. The model is defined as an elastic continuous beam (deck) on inelastic supports (piers and abutments) (Fig.1 step 4) [11]. The supports are characterised with the secant stiffness of the corresponding member in target displacement condition. To this aim, a force-displacement relation should be associated to piers and abutments. Other members such as shear keys and bearings are not explicitly considered in the model. Instead, their displacement capacity should be used in the post-processing phase to limit the global capacity.

The mechanical characterisation of the substructure members is needed. For this reason, accurate surveys, construction drawings and/or simulated design are generally needed. The nonlinear force-displacement law for single-column piers can be obtained based on Moment-Curvature relationships, calculated by a software such as KSU_RC [12], Cumbia [13], [14] or with analytical surrogate metamodels requiring few input data [15], [16]. In this calculation, the degree of fixity at the column top (and the torsional stiffness of the deck) should be considered, since this influences the stiffness and the displacement capacity of the pier. The effect of degrading shear strength, buckling of the bars and second-order effects [17]-[20] can be considered with appropriate modifications of the force-displacement laws. For simplicity, only flexure-prone piers are considered. The deck-abutment constraint condition should be modelled with appropriate force-displacement relations. In this work, a perfectly elastic behaviour with very high stiffness is assigned to pinned deck-abutment connections.

The DB-procedure provides the target displacement profile of the deck through the static analysis based-iterative calculations reported in Fig. 1, steps 1 to 4. An arbitrary control node is chosen (step 1) and a corresponding target displacement $\Delta_{c}$ is set. Such choice does not influence the final capacity curve. A tentative deformed (normalized) shape of the deck is initially guessed. If the first transverse mode is supposed to be dominant and the deck is reasonably restrained at the abutments, a sinusoidal or parabolic displacement shape is suggested to reduce the needed iterations. Useful formulation to choose the tentative deformed shape are reported in the work by Cardone [4]. Then, the displacement $\Delta_{i}$ is obtained for each member, scaling the shape such that the control node reaches $\Delta_{c}$. Using the force-displacement relations, the 
secant stiffness $k_{s e c, i}$ in target displacement condition is calculated for the piers and the abutments, and it is assigned to the supports of the simple beam model (step 2).

A static analysis is performed (step 3 - 4) assuming the distribution of inertia forces calculated with Eq. 1 , in which $V_{b}$ is the total base shear. Consequently, a new displacement profile $\left(\Delta^{\prime}{ }_{i}\right)$ is obtained and compared to the initial guess $\left(\Delta_{i}\right)$. Until convergence is achieved, the displacement profile is updated, and the process is repeated. Usually, three or four iterations are needed if a tolerance of $0,001 \mathrm{~m}$ is adopted.

$$
F_{i}=V_{b}\left(m_{i} \Delta_{i} / \sum_{i} m_{i} \Delta_{i}\right)
$$

Given the stabilised target displacement profile, the final step (step 5) provides the calculation of the equivalent SDoF displacement $\Delta_{e f f}$ (Eq. 2) and the associated total base shear $V_{b}$, that define a point on the pseudo-pushover capacity curve. Other equivalent SDoF proprieties, as effective mass $m_{e f f}$ (Eq. 3) can be calculated with reference to the formulations proposed by Priestley [1].

$$
\begin{gathered}
\Delta_{e f f}=\sum_{i} m_{i} \Delta_{i}^{2} / \sum_{i} m_{i} \Delta_{i} \\
m_{e f f}=\sum_{i} m_{i} \Delta_{i} / \Delta_{e f f}
\end{gathered}
$$

The pseudo-pushover curve is obtained repeating such calculations while increasing the control node target displacement (step 6), until one or more critical members reach their ultimate capacity. At the end of the process, a base shear $V_{b} v s$ effective displacement $\Delta_{e f f}$ curve is provided, which can be called "pseudo-capacity" curve since each point refers to a specific equivalent SDoF system $k$ having different effective mass $m_{e f f, k}$ and effective damping $\xi_{e f f, k}$. It is worth noting that the analysis is performed in an adaptive fashion [21], since for each step, a redistribution of inertia forces consistent with the actual stiffness of the members is considered.

Finally, the seismic performance assessment can be performed according to a capacity spectrum-based assessment approach. In this work, the Adaptive Capacity Spectrum Method (ACSM) proposed by Casarotti and Pinho [22] is used. In order to be compared with the demand, expressed as an Acceleration Displacement Response Spectrum (ADRS), the capacity curve should be converted in a capacity spectrum dividing the base shear $V_{b, k}$ associated to each SDoF system for the corresponding effective mass $m_{e f f, k}$. Once the Performance Point (PP) is calculated, it is compared to the capacity of the equivalent SDoF system. Moreover, the displacement/force of each substructure member can be obtained reading the results in the analysis database, and a local comparison between demand and capacity can be performed, if preferred.

It is worth noting that, if the user is not interested in obtaining the full-force displacement curve, a quick DBA of a bridge in any limit state condition can be performed through step 1 to 5. This short version of the procedure requires the identification of the critical node that characterises the investigated limit state. The deck target displacement of the SDoF system is calculated and the assessment can be performed with a displacement response spectrum approach as proposed by Priestley [1].

The above-mentioned concepts can be adapted for the longitudinal seismic response of the bridge, using a simplified model in which all supports/piers equipped with secant stiffness are forced to the same target displacement, reasonably assuming a rigid behaviour for the deck. 


\section{PARAMETRIC ANALYSIS}

The DB pseudo pushover is applied to investigate the seismic response of a set of 36 case study bridges having different structural regularity features. The accuracy of the procedure is evaluated, through a comparison with numerical pushover and time history analyses. The performance of the bridges is studied for three different levels of seismic intensity and, in turn, different ductility demand for the piers.

\subsection{Case study bridges}

The database is composed of 36 straight RC-bridges having pinned deck-pier connections. Those are meant to represent typical Italian bridge configurations. The case studies are chosen with different structural regularity features. Pioneering literature work [11] defines the regularity of a bridge according to the ratio of the transverse stiffness of the deck to the total lateral stiffness of the piers. Moreover, an irregular seismic response is registered in presence of piers of particularly-different stiffness along the deck [23]. To study this aspect, the case studies in this work are defined varying the deck transverse moment of inertia and the longitudinal distribution of piers having different heights, as indicated in Fig. 2.

Two deck configurations are chosen. The first (J50) is composed of three precast $1.80 \mathrm{~m}$ high girders connected through a $0.3 \mathrm{~m}$-thick, $11.50 \mathrm{~m}$-wide slab, for which the transverse moment of inertia is equal to $52.5 \mathrm{~m}^{4}$. The second configuration $(\mathrm{J} 100)$ has a moment of inertia for transverse flexure equal to $104.9 \mathrm{~m}^{4}$, since it is composed of four girders connected through a 14 m-wide slab. A specific type of pier cap is assigned to each deck configuration (Fig. 2). The total dead load (seismic condition) is equal to $185 \mathrm{kN} / \mathrm{m}$ and $230 \mathrm{kN} / \mathrm{m}$ for the $J 50$ and J100 configurations, respectively. Moreover, 8-, 15- and $20 \mathrm{~m}$-high piers are defined, having a

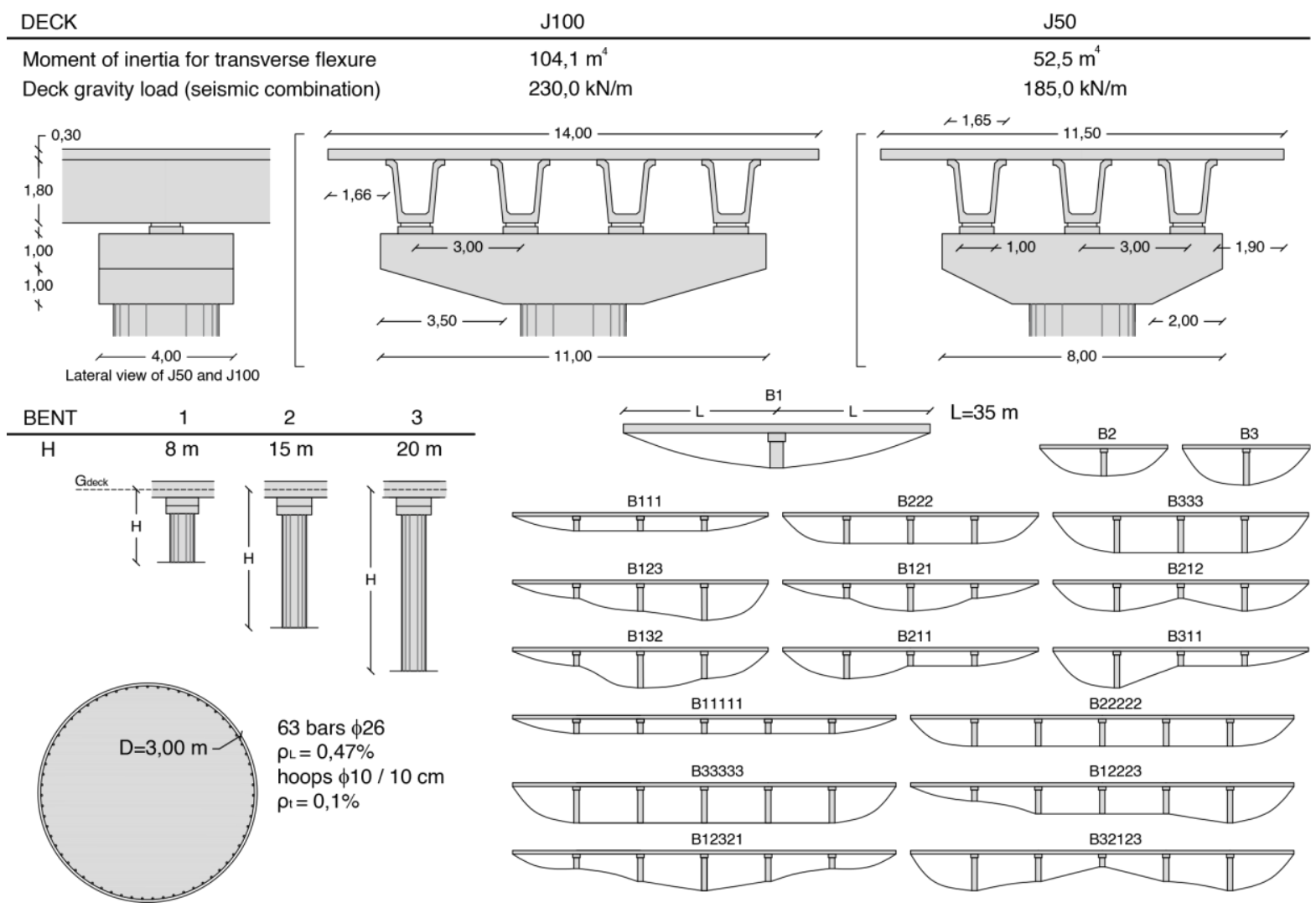

Figure 2: Selected case studies (Gentile et al. [6]). 
3 m-diameter circular section with 63 longitudinal bars $\Phi 26$ and $100 \mathrm{~mm}$-spaced $\Phi 10$ hoops. The considered strength for unconfined concrete $\left(f_{c}\right)$ and steel yielding stress $\left(f_{y}\right)$ are $20 \mathrm{MPa}$ and $450 \mathrm{MPa}$, respectively. The span length is constant and equal to $35 \mathrm{~m}$ for all the cases. Each bridge is identified by some digits that define the number and the heights of its piers. For example, B132 refers to a 4-bays bridge with the height of the piers respectively equal to $8 \mathrm{~m}$, $20 \mathrm{~m}$ and $15 \mathrm{~m}$.

\subsection{Modelling strategy and analysis assumptions}

The analytical DB-procedure is implemented in a MATLAB [7] function to perform the analysis, provide the pseudo-capacity curve and carry out the assessment. The force-displacement laws of the piers are calculated using a bi-linear Moment-Curvature relationship associated to the base-section. To this aim, the software CUMBIA [13] with the graphical user interface proposed by Gentile [14] is used. The model by Mander [24] is considered for the confined concrete and the model by King [25] is adopted for the steel reinforcements. The seismic masses are lumped in the main nodes of the superstructure and are calculated as the sum of the tributary deck mass, the mass of the pier cap, plus a third of the total pier mass. For simplicity, no strength degradation is considered beyond the ULS of the bridge.

Numerical models are created using the 3D software RUAUMOKO [26]. A lumped-plasticity model is used (Fig. 3): the piers are modelled as mono-dimensional elements with plastic hinges at the base section and secant stiffness at yielding. A revised Takeda "thin" law is used to consider the cyclic response. The deck is an elastic frame element equipped with uncracked stiffness with pinned connections at the piers and abutments. The abutments are modelled by elastic springs with very high lateral stiffness in transverse directions. The time-history analyses are carried out with natural scaled ground motions (section 3.3). The pushover analyses are performed in displacement-control with a first mode shape force profile. Further details about the modelling strategy are listed in Gentile et al. [6]. It is worth specifying that the numerical pushover results are plotted in base shear $V_{b} v s$ effective displacement $\Delta_{e f f}$ format to be compared with the DBPP procedure. The effective displacement is calculated adopting the effective mass consistent with each step and the corresponding performance points are computed with the ACSM.

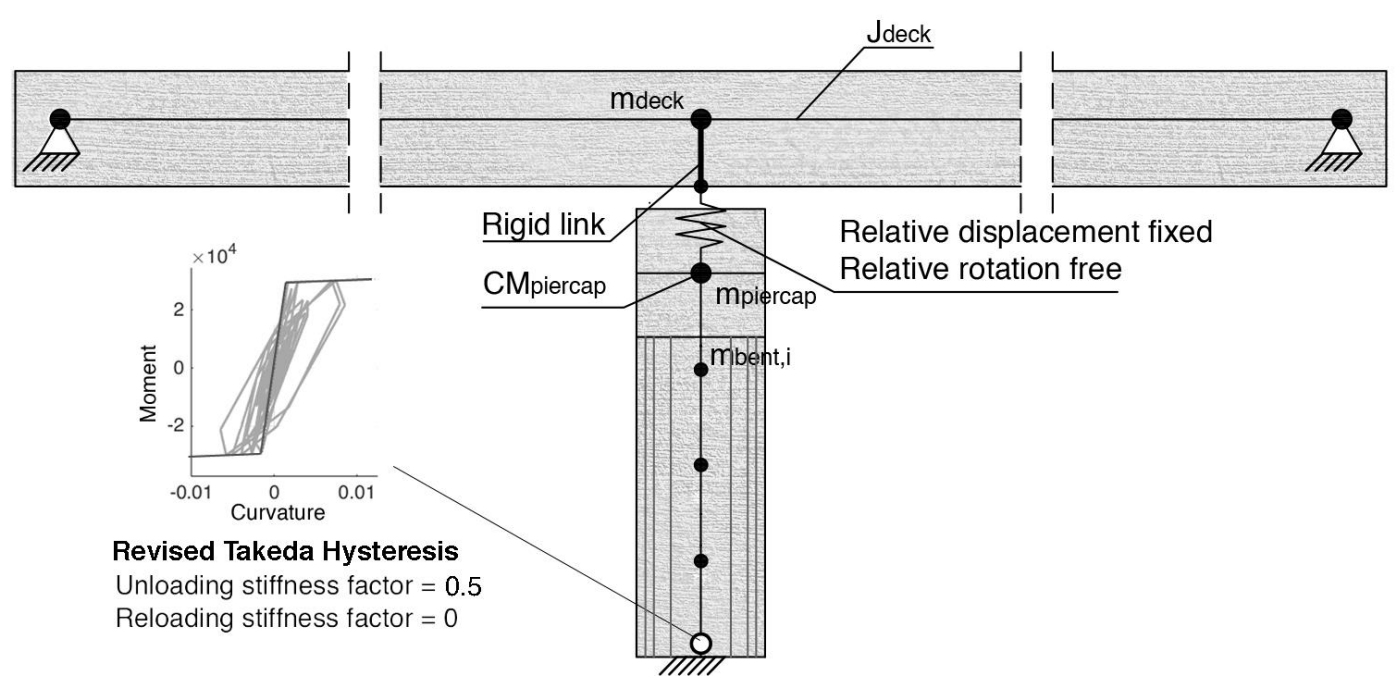

Figure 3: Modelling strategy 


\subsection{Seismic demand}

According to the Italian code [27], 5\%-damped demand spectra are chosen corresponding to three locations prone to high, medium and low hazard conditions (Fig. 4). The spectra are defined for a return period equal to 475 years and soil type $C$ corresponding to $180-360 \mathrm{~m} / \mathrm{s}$ shear wave velocity condition. The Peak-Ground Accelerations (PGA) adopted corresponds to 0,44g, $0,31 \mathrm{~g}$ and $0,21 \mathrm{~g}$. For each seismic demand level, a set of 10 scaled natural ground motions is selected using the software REXEL [28], from the European Strong Motions Database (ESD) and the Selected Input Motions for displacement- Based Assessment and Design (SIMBAD) database. The selected accelerograms are linearly-scaled in amplitude to meet the spectrumcompatibility criteria prescribed by the Italian Code. The compatibility is ensured in a $0,1-2 \mathrm{~s}$ period matching bandwidth that includes the first mode periods of the entire database of case studies.

\subsection{Definition of CDR and BI}

Given the wide results dataset, two simple indexes are calculated for each bridge and each seismic demand level: the Capacity Demand Ratio and the Bridge Index. In the post-processing of results, it is assumed that the ULS of a bridge is reached when one of the piers achieves its ultimate displacement capacity $\Delta_{\text {pier }, i}^{U}$. Consequently, the Capacity Demand Ratio (CDR) informs about the seismic performance of each case and is calculated for both the Non-linear Static Procedures, DBPP and pushover, (NSP in the following), with Eq. 4, in which $\Delta_{p i e r, i}^{P P, j}$ is the displacement demand of the pier $i$ at the performance point for seismic demand $j$. For the time-history analysis, the $C D R$ is calculated with $\Delta_{p i e r, i}^{T H, j}$ that is the average response of the 10 ground motions of the considered seismic intensity level $j$.

$$
C D R_{j}^{N S P / T H}=\min \left(\frac{\Delta_{\text {pier }, i}^{U}}{\Delta_{p i e r, i}^{P P / T H}, j}\right)
$$

It is worth noting that the $C D R$ considers only the capacity and the demand displacement of the critical pier. To easily compare the reliability of the NSPs to the TH, the parameter
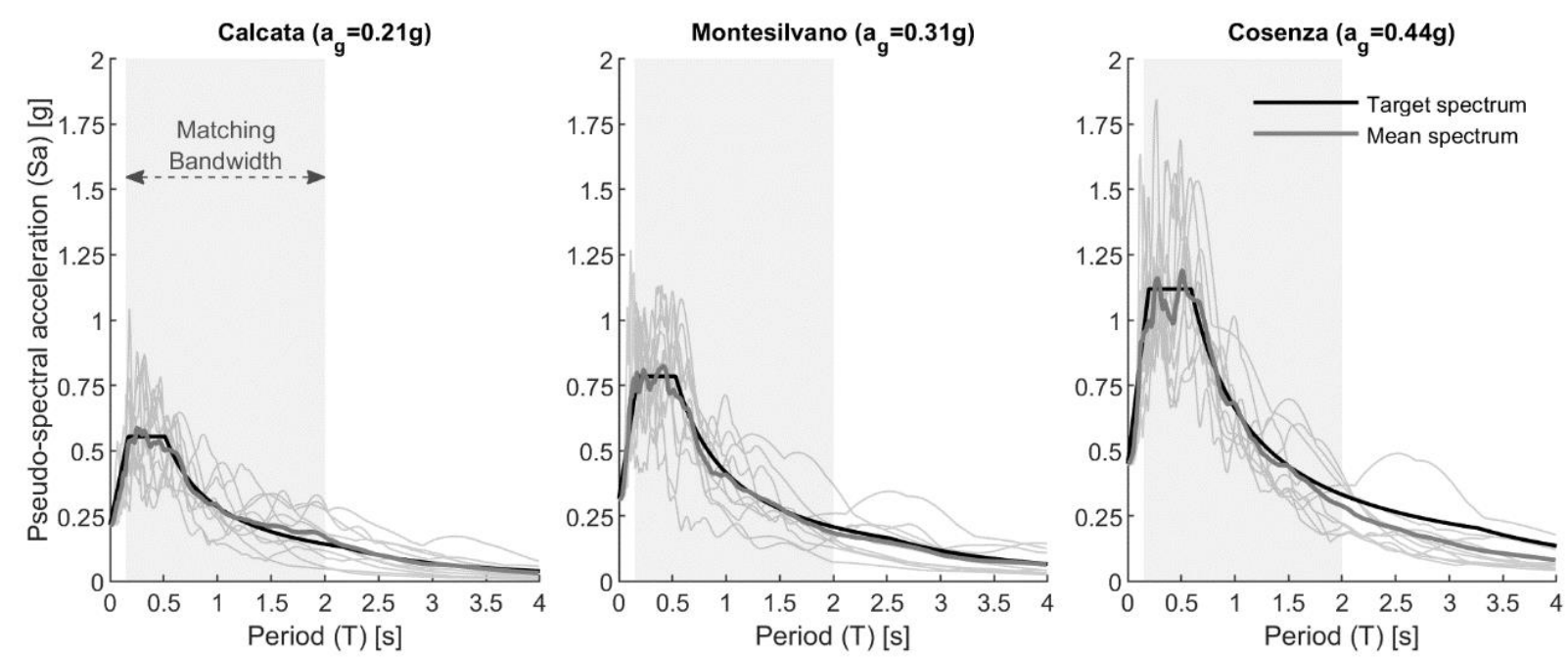

Figure 4: Code and mean elastic spectra of the selected ground motions 
$\operatorname{err} C D R^{N S P}$ is introduced expressing the relative error between the $C D R$ calculated for the TH and analogous value of the NSP (Eq. 5). The CDRs for the entire dataset are reported in Fig. 7.

$$
\operatorname{errCDR_{j}^{NSP}}=\frac{C D R_{j}^{T H}-C D R_{j}^{N S P}}{C D R_{j}^{T H}} \times 100
$$

The second index used is the Bridge Index (BI), proposed by Pinho [29] and modified by Kohrangi [30]. It is adapted in this work to discuss the accuracy to predict the shape (normalized) of the target displacement profile of the NSPs with reference to the more refined time-history. The $B I$ is calculated with Eq. 6 as the mean of the ratios between the coefficients $\delta_{i}^{P P}$ and $\delta_{i}^{T H}$, which are respectively the normalized NSPs target displacement and the average TH normalized displacement. Moreover, the range of the $B I$, including the $\min / \max \left(\delta_{i}^{P P j} / \delta_{i}^{T H j}\right)$ is used to discuss the results. BIs are reported in Fig. 8.

$$
B I_{j}^{N S P}=\operatorname{mean}\left(\frac{\delta_{i}^{P P j}}{\delta_{i}^{T H j}}\right)
$$

\section{PARAMETRIC STUDY RESULTS}

In this section, the results of the DBPP approach are compared with a standard numerical pushover analysis (including CSM), and more refined non-linear time history analyses. It is worth specifying that a preliminary modal analysis, performed with the refined numerical models, shows that the participating mass of the first mode exceeds the $70 \%$ in all the cases. This makes the case studies suitable to be analysed with a first mode-based pushover and the proposed DBPP, excluding meaningful higher mode contributions. Firstly, the results about selected sample cases are discussed, then considerations about the entire dataset are provided.

\subsection{Results of regular and irregular sample cases}

To help the reader interpreting the wide set of results represented systematically with $B I S$ and $\operatorname{errCDRs}$, the results of the $J 100-B 222$ (Fig. 5) and J50-B211 (Fig. 6) bridges are discussed in detail. These cases are representative of regular and irregular configurations, respectively.
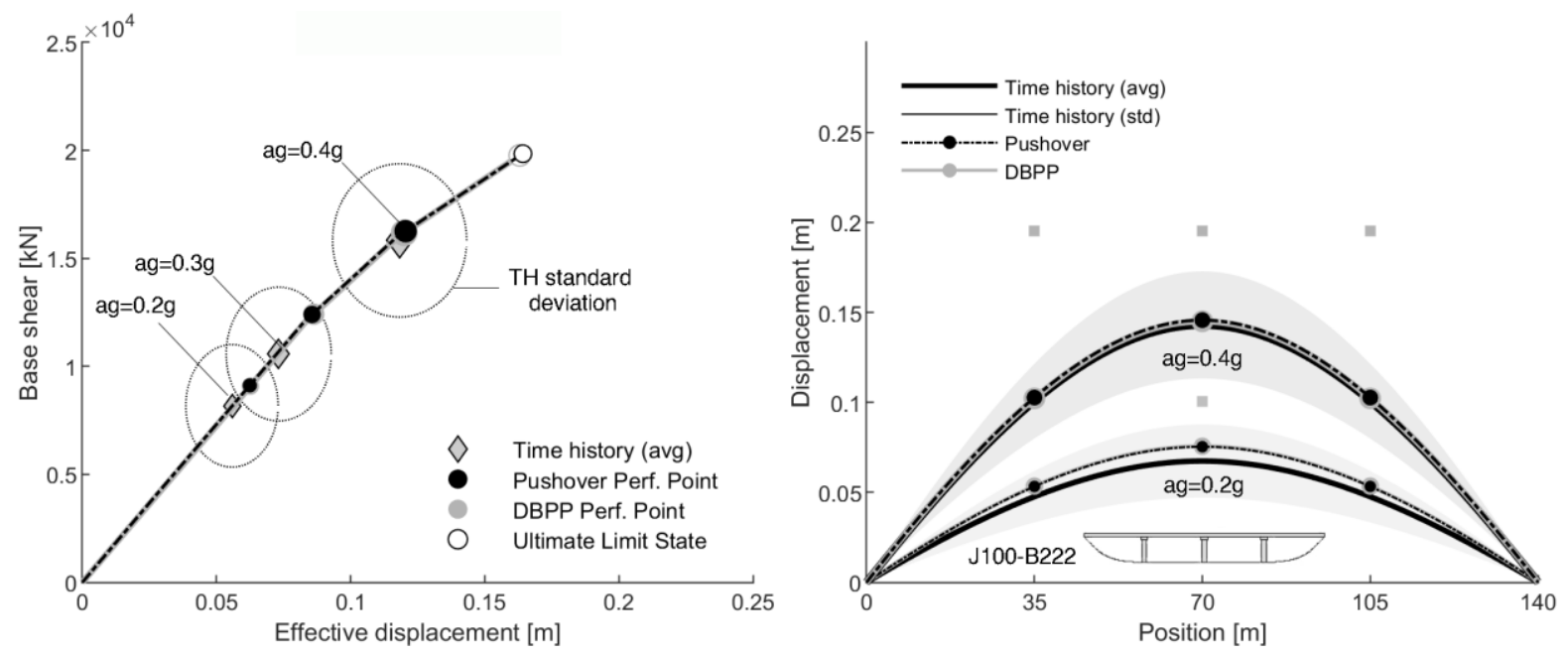

Figure 5: Capacity curve and target displacement profiles for J100-B222 case 

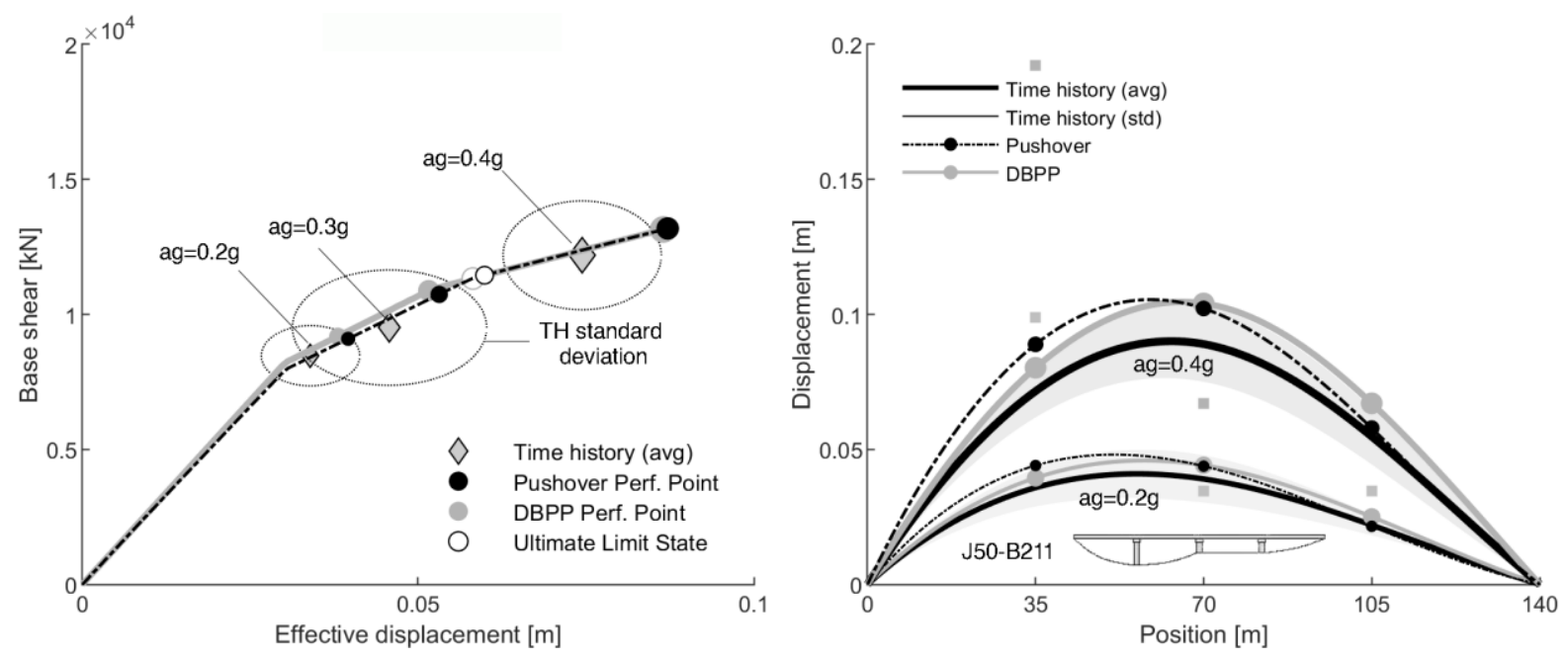

Figure 6: Capacity curves and target displacement profiles for the J50-B211 case

Regardless of the regularity, the DBPP capacity curve is consistent with the numerical pushover, proving the accuracy of the proposed method.

In the J100-B222, the differences between the adaptive DBPP and pushover performance displacement profiles are negligible, and displacement profile of the deck is basically invariant (parabolic shape for all demand levels). This proves that the spatial distribution of stiffness of the piers and their degradation do not influence the bridge regular seismic behaviour. For every intensity level, the $B I$ assume unitary values (with negligible dispersion) providing that the deformed shape is well-predicted. Such a regular response is due to the high stiffness of the deck J100 compared to the (low) lateral stiffness of the 15m-high piers. Consequently, the PPs derived by the investigated NSPs are consistent, regardless of the seismic demand level. Indeed, the DBPP-based $C D R$ is practically equal to the pushover-based one obtained, while the maximum $\operatorname{errCDR}$ (with respect to the $\mathrm{TH}$ ) is equal to $14,46 \%$ and $15,07 \%$ for DBPP and pushover, respectively (considering the mid-intensity set).

The J50-B211 bridge is characterised by a low stiffness of the deck and an asymmetric shape with short piers that strongly influence its dynamic response. Although the force-displacement curves are particularly similar, some differences between the DBPP and the pushover analyses emerge. Analysing the performance displacement profiles for the low seismic demand levels, it is evident that, when one of the short piers reaches its yield displacement, the displacement shape changes compared to the elastic phase. Since an invariant, first-mode force profile is used in the pushover, it fails to predict the performance point displacement profile with respect to the time history analysis. With reference to the deformed shapes, for all the demand levels, the pushover overestimates the displacement of the more deformable pier of the bridge, underestimating it for the stiffer one(s). For this reason, the corresponding $B I$ is approximately equal to one but exhibits a wide dispersion. The DBPP succeeds in better-predicting the displacement shape with respect to the TH, since it is "adaptive". The BI is practically equal to one and a negligible dispersion for low seismic demand is registered. For the highest seismic demand, a higher error is registered for the DBPP-based $B I$, proved by its higher dispersion. This indicates the lower accuracy of the DBPP for high intensity and particularly-irregular bridges, although in many cases it outperforms the numerical pushover. Further research is needed to investigate the adaptive properties of the DBPP. 


\subsection{Results for the entire set of case studies}

The DBPP is particularly accurate for the 2-bays subset, since it provides extremely similar errCDRs compared to the pushover, regardless of the typology of the deck and the piers. For all the demand levels, the 2-bays bridges respond elastically, since the high stiffness of the superstructure governs the seismic behaviour, transferring the majority of the base shear to the abutments. Regarding the 4-bays subset, the main differences between the pushover- and DBPP-based $C D R s$ are detected for $B 121, B 123, B 132$ for the low seismic demand. In these cases, the target displacement profiles of the NSPs differs considerably since if the shortest pier is the only one yielding, the DBPP modifies the force profile, while the pushover is unable to do so. The corresponding BI dispersion shows that the adaptive DBPP outperforms the pushover in predicting the deformed shape for low seismic intensity. In most 6-bays cases, the BIs indicate that the DBPP outperforms the pushover in predicting the target deformed shape,

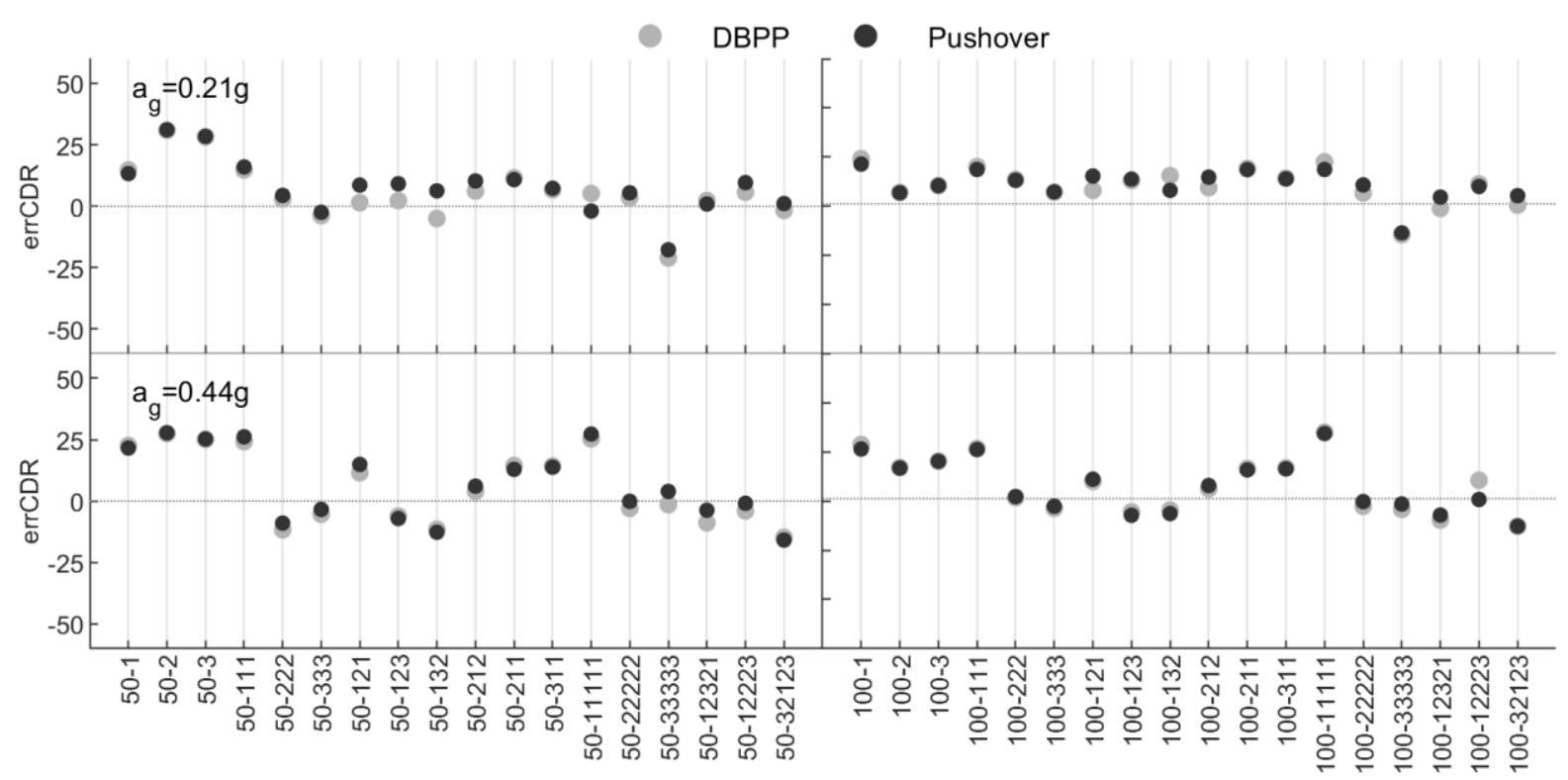

Figure 7: errCDR for the entire set of case studies

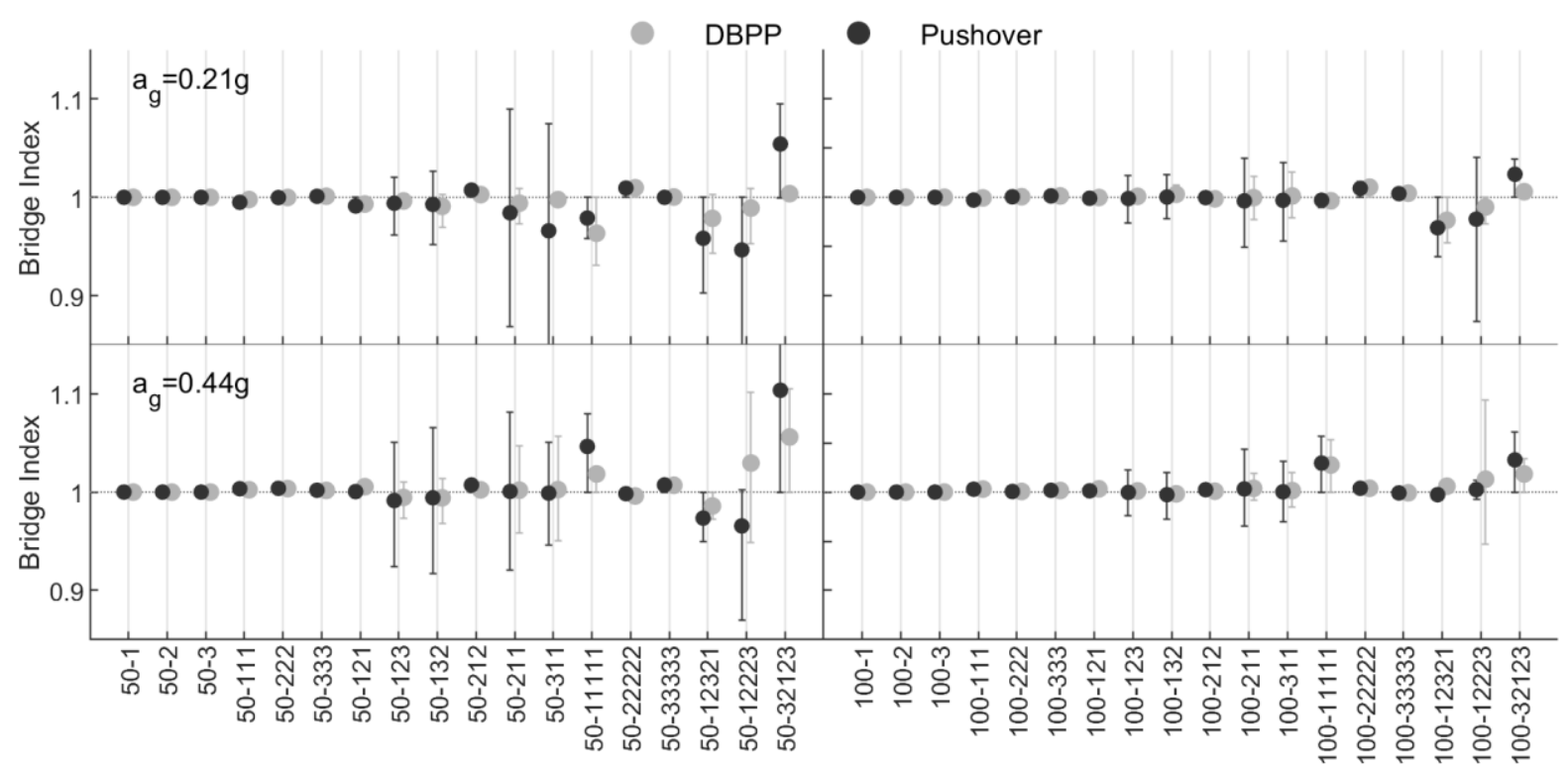

Figure 8: BI for the entire set of case studies 
regardless of the seismic intensity. It is worth noting that, for 6-bays bridges, the differences detected between DBPP and pushover compared to the average TH are higher than for the other subsets. In these cases, the accuracy of the pushover decreases because, given that the lower regularity of the bridge, an invariant method is insufficient.

Comparing the CDRs and BIs of the J50 and J100 subset, increasing the deck stiffness and consequently the regularity of the bridge, the differences between DBPP and pushover decreases. This is because the influence of the piers on the deck seismic behaviour decreases (the deck governs) and the shape of the target displacement profiles is almost invariant regardless of the increasing ductility demand (depending on the seismic intensity).

Generally, with reference to the Tab. 1, it can be claimed that the proposed DBPP is a fairly accurate procedure. The mean of the absolute errCDRs of the various subsets indicate that the DBPP provides a comparable accuracy than the pushover.

\begin{tabular}{|c|c|c|c|c|c|c|c|}
\hline \multirow{2}{*}{\multicolumn{2}{|c|}{ Set }} & \multicolumn{2}{|c|}{ PGA $=0,21 \mathrm{~g}$} & \multicolumn{2}{|c|}{ PGA $=0,31 \mathrm{~g}$} & \multicolumn{2}{|c|}{ PGA $=0,44 \mathrm{~g}$} \\
\hline & & errCDR $R_{\text {push }}$ & err $C D R_{D B P P}$ & errCDR $R_{\text {push }}$ & err $C D R_{D B P P}$ & errCDR $R_{\text {push }}$ & errCDR $R_{D B P P}$ \\
\hline \multirow[t]{2}{*}{ 2bays } & J50 & 24,26 & 24,63 & 13,98 & 14,22 & 24,85 & 25,06 \\
\hline & $\mathrm{J} 100$ & 10,34 & 11,12 & 20,46 & 21,14 & 16,94 & 17,60 \\
\hline \multirow[t]{2}{*}{ 4bays } & J50 & 8,37 & 6,06 & 11,37 & 10,06 & 9,09 & 8,87 \\
\hline & $\mathrm{J} 100$ & 11,01 & 10,71 & 11,66 & 11,68 & 8,53 & 8,17 \\
\hline \multirow[t]{2}{*}{ 6bays } & J50 & 6,12 & 6,57 & 8,49 & 7,70 & 8,63 & 9,56 \\
\hline & J100 & 7,33 & 5,96 & 5,03 & 5,15 & 5,70 & 8,04 \\
\hline
\end{tabular}

Table 1: Average of $\operatorname{errCDR}$ for 2, 4 and 6-bays subset

\section{CONCLUSION}

This work deals with the parametric validation of a displacement-based pseudo-pushover (DBPP) procedure to investigate of the seismic performance of straight, continuous deck RC bridges, recently proposed by Gentile et al. [6]. It allows to have the full force-displacement relation expressed in terms of equivalent SDoF proprieties. The simplicity of the procedure is evident, since it is based on a simplified mechanical model of the bridge and linear static analyses with secant stiffness related to increasing displacements. Coupled with a capacity spectrum based-assessment method, the procedure allows the seismic performance assessment of the bridge for a given level of the seismic intensity.

The DBPP is compared with pushover analyses and refined time-history analyses carried out with 3 suites of 10 natural ground motions scaled according to three different levels of the seismic intensity. The procedure is herein applied on 36 bridge case studies having different structural regularity features, deck configurations, number of bays and height of the piers. The results are discussed in detail for two selected case studies and then systematically illustrated for the entire dataset, adopting parameters such as the Capacity Demand Ratio and the Bridge Index.

The results show that the DBPP and the pushover provide particularly similar results, with similar bias if compared to the time-history analyses. Given its adaptive fashion, for the more irregular case studies, the DBPP succeeds in better predictions of the target deformed shape compared to standard pushover analyses. This parametric analysis demonstrated that the DBPP can represent a suitable tool for practitioners, at least for bridges similar to the analysed ones. Moreover, this work demonstrates that DBPP can be performed using quick implementations in spreadsheets or code functions that require low computational effort. Provided that extensions are developed to consider other bridge typologies, DBPP could result particularly suitable for mechanics-based regional-scale investigations on large portfolio of bridges, especially if implemented in a GIS environment. 


\section{ACKNOWLEDGEMENTS}

The research presented in this article was partially funded by the Italian Department of Civil Protection in the framework of the national project DPC-ReLUIS 2014-2018.

\section{REFERENCES}

[1] M. J. Priestley, M.J.N., Calvi, G.M., Kowalsky, Displacement-Based Seismic Design of Structures. Pavia, Italy: IUSS Press, 2007.

[2] O. B. Şadan, L. Petrini, and G. M. Calvi, "Direct displacement-based seismic assessment procedure for multi-span reinforced concrete bridges with single-column piers," Earthq. Eng. Struct. Dyn., 2013.

[3] M. J. Kowalsky, "A displacement-based approach for the seismic design of continuous concrete bridges," Earthq. Eng. Struct. Dyn., vol. 31, no. 3, pp. 719-747, 2002.

[4] D. Cardone, "Displacement limits and performance displacement profiles in support of direct displacement-based seismic assessment of bridges," Earthq. Eng. Struct. Dyn., 2014.

[5] P. Ni, L. Petrini, and R. Paolucci, "Direct displacement-based assessment with nonlinear soil-structure interaction for multi-span reinforced concrete bridges," Struct. Infrastruct. Eng., vol. 10, no. 9, pp. 1211-1227, 2014.

[6] R. Gentile, A. Nettis, and D. Raffaele, "Effectiveness of the Displacement-Based seismic performance Assessment for continuous RC bridges and proposed extensions," (submitted).

[7] The MathWorks Inc., "MATLAB . version 9.5.0.944444 (R2018b)." Natick, Massachusetts:, 2018.

[8] D. Raffaele, F. Porco, A. Fiore, and G. Uva, "Simplified vulnerability assessment of reinforced concrete circular piers in multi-span simply supported bridges," Struct. Infrastruct. Eng., vol. 10, no. 8, pp. 950-962, 2014.

[9] A. Fiore, F. Porco, D. Raffaele, and G. Uva, "Simplified assessment of seismic retrofitting interventions on RC circular piers in multi-span simply supported bridges," in Bridge Maintenance, Safety, Management and Life Extension, 2014, pp. 2253-2261.

[10] NZSEE - New Zealand Society for Earthquake Engineering, "The seismic assessment of existing buildings - technical guidelines for engineering assessments." Wellington, New Zealand, 2017.

[11] M. J. N. Priestley, F. Seible, and G. M. Calvi, Seismic design and retrofit of bridges. New York, USA: John Wiley and Sons, 1996.

[12] A. Esmaeily and R. J. Peterman, "Performance analysis tool for reinforced concrete members." Computers and Concrete, p. 4:331-346, 2007.

[13] L. A. Montejo and M. J. Kowalsky, "Set of codes for the analysis of reinforced concrete members," Environmental Engineering, no. February 2007. North Carolina State University, Railegh, North Carolina.

[14] R. Gentile, "RC Section Rect - practical manual. Free internal report and software." 2017. 
[15] R. Gentile and D. Raffaele, "Simplified analytical Moment-Curvature relationship for hollow circular RC cross-sections," Earthq. Struct., vol. 15, no. 4, pp. 419-429, 2018.

[16] R. Gentile, F. Porco, D. Raffaele, and G. Uva, "Simplified moment-curvature relationship in analytical form for circular RC sections," Bull. New Zeal. Soc. Earthq. Eng., vol. 51, no. 3, pp. 145-158, 2018.

[17] D. Raffaele, A. Fiore, G. Uva, and F. Porco, "About of seismic capacity of bridge piers: A simplified approach," in Bridge Maintenance, Safety, Management and Life Extension, 2014, pp. 2245-2252.

[18] D. Raffaele, G. Uva, F. Porco, and A. Fiore, "Buckling of Rectangular Isolated R.C. Columns: Closed-form Approximation for Interaction Domains," Open Constr. Build. Technol. J., vol. 7, no. 1, pp. 129-137, 2013.

[19] M. P. Berry and M. O. Eberhard, "Practical Performance Model for Bar Buckling," J. Struct. Eng., 2005.

[20] M. J. Kowalsky and M. J. N. Priestley, "Improved analytical model for shear strength of circular reinforced concrete columns in seismic regions," ACI Struct. J., 2000.

[21] S. Antoniou, R. Pinho, and C. A. Volta, "Development and verification of a displacement-based adaptive pushover procedure," J Eq Eng, vol. 8, no. 5, pp. 643-661, 2004.

[22] C. Casarotti and R. Pinho, "An adaptive capacity spectrum method for assessment of bridges subjected to earthquake action," Bull. Earthq. Eng., 2007.

[23] T. Isakovic, "Higher modes in simpliÿed inelastic seismic analysis of single column bent viaducts," no. April 2005, pp. 95-114, 2006.

[24] I. Buckle, I. Friedland, J. Mander, M. Geoffrey, R. Nutt, and M. Power, "Seismic Retrofitting Manual for Highway Structures : Part 1 - Bridges," Fhwa, no. January, 2006.

[25] D. J. King, M. J. N. Priestley, and R. Park, "Computer programs for concrete column design, Research Report 86/12.” University of Canterbury - Department of Civil Engineering, Christchurch, New Zealand, 1986.

[26] A. J. Carr, "Ruaumoko Manual Author :," vol. 2, 1981.

[27] M. D. Infrastrutture and E. D. E. I. Trasporti, "Aggiornamento delle «Norme tecniche per le costruzioni».," pp. 1-198, 2018.

[28] I. Iervolino, C. Galasso, and E. Cosenza, "REXEL: Computer aided record selection for code-based seismic structural analysis," Bull. Earthq. Eng., 2010.

[29] R. Pinho, C. Casarotti, and S. Antoniou, "A comparison of single-run pushover analysis techniques for seismic assessment of bridges," Earthq. Eng. Struct. Dyn., 2007.

[30] M. Kohrangi, R. Bento, and M. Lopes, "Seismic performance of irregular bridges comparison of different nonlinear static procedures," Struct. Infrastruct. Eng., vol. 11, no. 12, pp. 1632-1650, 2015. 